\title{
The use of non-metal materials in the filler units of cooling towers with circulating water supply system
}

\author{
Andrey V. Dmitriev ${ }^{1}$, Ilnur N. Madyshev ${ }^{2, *}$, and Aliya I. Khafizova ${ }^{2}$ \\ ${ }^{1}$ Kazan State Power Engineering University, 420066, Kazan, Krasnoselskaya str., 51, Russia \\ ${ }^{2}$ Kazan National Research Technological University, 420015, Kazan, Karl Marx str., 68, Russia
}

\begin{abstract}
The design of cooling tower's filler unit, consisting of inclinedcorrugated contact elements, and made of polymer material, is developed and described in this research paper. The experimental studies were conducted to determine the efficiency of cooling the circulating water in the proposed cooling tower. The authors obtained the results of evaluating the heat-mass transfer efficiency coefficient of cooling tower, when changing the mass flow rates of liquid and gas phases. The research results showed that the highest efficiency of cooling the circulating water is observed at relatively low irrigation densities equal to $15-25 \mathrm{~m}^{3} /\left(\mathrm{m}^{2} \cdot \mathrm{h}\right)$, while the heat-mass transfer efficiency of cooling tower achieves $72 \%$.The use of non-metal materials as the main elements of cooling tower allows to abandon the use of chemical reagents against bacteria and microorganisms in favor of circulating water ozonation method.
\end{abstract}

\section{Introduction}

The circulating water supply at the enterprises of many industries, such as chemical, energy, petrochemical and others is increased every year, allowing to reduce the use of water from natural sources, thereby preventing the environmental pollution and contamination.

The circulating water supply at the industrial enterprises often acts as a cooler or heat carrier, while cooling the main process equipment. The further cooling of water takes place in cooling towers. The most common are the fan-type evaporative cooling towers, where liquid is cooled by its contact with air, as well as due to the partial evaporation of water. The evaporated part of liquid is replenished with the feed water from a natural source. The surface water sources contain huge concentrations of suspended substances. Liquid is pretreated and settled in reservoirs, purified in settling tanks, but it is not uncommon for water to enter the cooling tower directly from a natural source. Thus, a huge amount of various deposits accumulate on the surface of equipment, which have a negative impact on the performance of cooling tower, starting with the disruption of liquid flow structure and finishing with the destruction of cooling equipment. Another source of contamination of

\footnotetext{
Corresponding author: ilnyr 91@mail.ru
} 
circulating water supply systems is the flow of atmospheric air, containing dust. The dust particles are captured by liquid drops and settle on the surface of cooler. Also, the environment inside the cooling tower, including oxygen in water, is favorable for the development and reproduction of bacteria and microorganisms on the surface of cooler [1, 2].

A huge number of mechanisms are developed to fight against contamination, such as chemical treatment of water with reagents, mechanical disinfection, reagent-free, etc. The chemical treatment of circulating water supply system is widely used, but this method requires huge economic costs for the purchase of chemical reagents, in addition, the reagents themselves have an adverse impact on the environment. In this regard, new ways to prevent contamination are being searched every day. The well-known methods of water treatment are magnetic and ultrasonic. However, these methods do not allow us to prevent the formation of biological and mechanical deposits completely in the circulating water supply systems [3].

There is also another highly effective method for controlling the organic contamination - the method of water ozonation. The ozonation allows to remove hard-to-reach contaminations, disinfects and softens water, washes away previously formed deposits. Ozone effectively oxidizes metal compounds, so this method cannot be applied for metal coolers [4].

The fillers are the main structural elements of cooling tower that determine its cooling capacity. The filler is a contact device on the surface and in the volume of which the processes of heat, mass and momentum transfer take place [5-18].

In order to create contact devices, various types of materials are used, such as wood, metal, and polymers $[19,20]$. For a long time, wooden checker filling units were very popular. The main advantage of them is that the surface has a high wettability, and the distribution of water on the surface of unit is even with the liquid film formation. However, there is an important drawback - they are not durable (short service life). Wood, due to its nature, regardless of treatment methods, under prolonged exposure to water, quickly rottens and destroys. Wooden checker filling units are also subject to high chemical and biological effects. Very often at different enterprises you can find contact devices, made of metal. In comparison with wooden contact devices, the metal ones are more durable, while the same as wood ones have good wettability. However, the manufacturing of contact device structures from metal is very expensive and material-intensive. Moreover, carbon steels of ordinary quality are not resistant to corrosion.

The checker filling units, made of polymer materials are widely used today [21]. These units are not affected by many chemical compounds and characterized by cheapness and durability. However, the polymer materials, compared to wooden and metal ones for the checker filling units, do not have good wettability, therefore, in order to achieve high cooling efficiency, it is necessary to intensify the heat-mass transfer processes by applying various roughnesses, porosities, perforations to the surface of polymers, as well as other methods of intensification.

The organization of technological process in the circulating water supply system implies taking into account the above requirements, as well as the use of checker filling unit design, which allows to increase the efficiency of cooling process, to reduce energy costs with minimal hydraulic resistance of contact devices.

\section{Description of the device and its operation}

The authors of this research paper developed a fan-type evaporative cooling tower, with the use of inclined-corrugated contact device. The main elements of cooling tower are the fan that provides air flow, the filler unit for distributing the liquid flow, the catchment basin and 
the water pump for liquid pumping [22].

The main process (technological) elements of cooling tower are made of polymer material, which allows to abandon the use of chemical reagents against bacteria and microorganisms in favor of water ozonation method.

The filler unit is a block of inclined-corrugated plates with round-shaped holes, executed along the entire working surface (Fig. 1). The plates have rounded profile corrugations, in the hollows of which the liquid film flows down. The corrugations on the surface of heat-mass transfer create significant turbulence of moving liquid at a relatively low flow rate. The material for the elements of cooling tower's checker filling unit, in particular, the inclined-corrugated plates, is polyethylene of low-pressure. The main reason for choosing the polymer materials for the cooling tower's checker filling unit is durability, cost-effectiveness, and ease of manufacture. In addition, it can be noted that polymers have good corrosion resistance, thermal and electrical insulation properties, high strength, and are resistant to temperature impact. Very often, chemical reagents are used to purify the circulating water from bacteria and microorganisms, which have almost no impact on the composite materials, due to their resistance to chemicals. The developed design of contact devices, made of polymer materials, provides convenience and compactness for longdistance transportation [23].

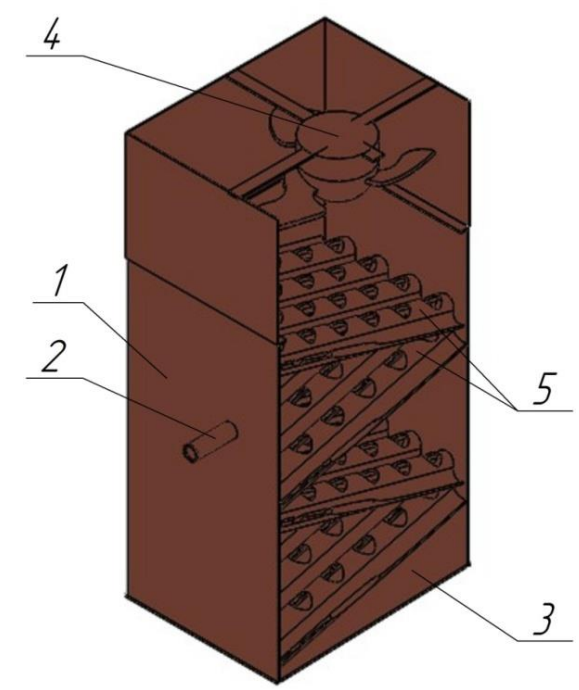

Fig. 1. The fan-type evaporative cooling tower with self-distribution of liquid: 1 - shell 1 casing; 2 liquid supply manifold; 3 - basin for liquid collection; 4 - fan; 5 - filler, consisting of corrugated plates.

The circulating water in cooling tower is cooled as follows: hot used water enters the inclined-corrugated checker filling unit through the distribution device. The design of cooling tower allows you to avoid using a huge number of switchgears that is, undoubtedly, an advantage. Liquid enters onto the surface of corrugated plate and contacts with the upward air flow, then breaks and flows down the recesses of plate to the next stage and thus reaches the catch basin. A part of liquid falls through the holes within the plate. Atmospheric air enters the cooling tower, moves in the volume of checker filling unit under the action of fan, passes through the holes within the inclined-corrugated plates, while involving a part of liquid with it, which is further sprayed throughout the entire volume of contact device. After that it is thrown on the walls of filler unit, while breaking the surface of moving liquid film and, thereby, creates a highly developed contact surface of gas and liquid phases. Water is cooled by a direct contact of phases in the form of film, splashes, 
drops, liquid bubbling, water flow turbulence on the surface of plates, while there is an active evaporation of a part of liquid.

Due to the given design solution, water in the volume of filler unit is distributed independently and evenly, filling almost the entire volume of contact device, while the manufacturing of device from polymer material is the most appropriate.

\section{Description of the study and its results}

In order to determine the efficiency of developed fan-type evaporative cooling tower with the inclined-corrugated contact elements, an experimental unit for conducting physical experiments was developed. This unit allows to conduct the heat-mass transfer processes upon condition of countercurrent movement of two phases, and to study the hydrodynamic processes in the contact device. In the course of experiments, the hydraulic resistance of inclined-corrugated contact elements, its heat efficiency coefficient and the efficiency of heat-mass transfer processes were determined.

The experimental unit consists of two-stage block of inclined-corrugated plates with a total height of $340 \mathrm{~mm}$. The corrugated plates have a rounded profile with a radius of 7.5 $\mathrm{mm}$. The round-shaped holes with a diameter of $6 \mathrm{~mm}$ are executed on the side surfaces and within the upper part of corrugations. The cross-section dimensions of apparatus, under the study, are of 100x100 mm.

The experiments were conducted in a two-phase air-water system. Water entered the upper central part of the first contact stage at various mass flow rates, which was measured by means of rotameter. At the inlet and outlet of apparatus, the liquid temperature was measured by a two-channel meter-regulator OBEH 2TPM1, while the temperature of hot water varied within the range of $37.1-43.8^{\circ} \mathrm{C}$. The fictitious cooling air flow rate was measured by means of testo $405 \mathrm{i}$ thermal anemometer with a relative error of not more than $5 \%$. The measured value range of this portable device is from 0 to $30 \mathrm{~m} / \mathrm{s}$. The fictitious gas rate for the full cross-section of contact device during the physical experiment varied within the range of $1.4-3.5 \mathrm{~m} / \mathrm{s}$. The irrigation density varied within the range of $12-37 \mathrm{~m}^{3} /\left(\mathrm{m}^{2} \cdot \mathrm{h}\right)$. In the course of experiment, the relative air humidity, determined by means of testo $605 \mathrm{i}$ thermohygrometer, varied within the range of $49.7-57.2 \%$. The pressure drop along the height of contact device was measured by means of testo $510 \mathrm{i}$ differential pressure gauge.

In the course of experiment, it was found that the range of operating air rates for the stable operation of contact device without liquid entrainment is quite wide and varies from $1.7 \mathrm{~m} / \mathrm{s}$ to $3 \mathrm{~m} / \mathrm{s}$, the maximum value of which corresponds to the beginning of "suspension" regime. The liquid bubbling is revealed during visual observation that has a significant impact on the efficiency of water cooling in the proposed contact device. The value of hydraulic resistance of device does not exceed 2.5 , and is quite low among existing analogues [24-28].

For a more complete understanding of the proposed design efficiency, the heat efficiency coefficient and water evaporation efficiency coefficient were determined [29].

Analyzing the graphs shown in Fig. 2, the following conclusions can be made: the heat efficiency coefficient of cooling tower with inclined-corrugated contact elements reaches $32 \%$, which corresponds to the technical data for the modern filler units with highefficiency, widely used at the enterprises of different industries. It is obvious that with an increase in the irrigation density, the value of heat efficiency coefficient decreases, and with an increase in fictitious air flow rate, vice versa, increases. This is primarily due to the fact that with an increase in water consumption, liquid fills the whole volume of inclinedcorrugated contact device, thereby preventing the movement of air flow. With an increase in the fictitious air flow rate, the phenomenon of liquid bubbling is observed; a large number of splashes and drops are formed that fly out from the liquid surface, which leads to 
an increase in the cooling efficiency of circulating water.
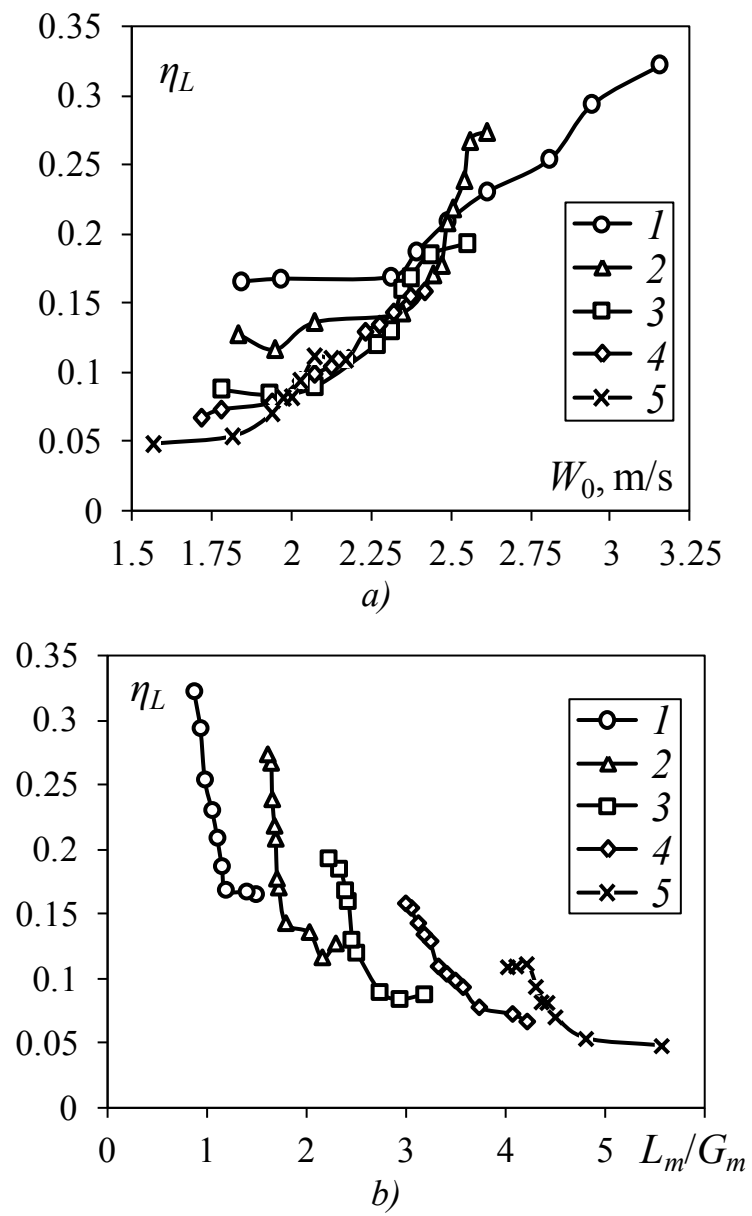

Fig. 2. The dependency of change in the heat efficiency coefficient on the fictitious air rate $(a)$ and the ratio of mass flow rates of liquid and gas phases $(b)$ at different irrigation densities $q, \mathrm{~m}^{3} /\left(\mathrm{m}^{2} \cdot \mathrm{h}\right)$ : $1-12 ; 2-18 ; 3-24 ; 4-31 ; 5-37$.

When determining the value of efficiency of heat-mass transfer processes during water evaporation in the inclined-corrugated contact elements, it was found that the highest efficiency is equal to $72 \%$ (Fig. 3). It is observed at relatively low irrigation densities, equal to $15-25 \mathrm{~m}^{3} /\left(\mathrm{m}^{2} \cdot \mathrm{h}\right)$. With further increase in the irrigation density, the heat-mass transfer efficiency of cooling tower is usually reduced. For example, an increase in the irrigation density from $18 \mathrm{~m}^{3} /\left(\mathrm{m}^{2} \cdot \mathrm{h}\right)$ to $37 \mathrm{~m}^{3} /\left(\mathrm{m}^{2} \cdot \mathrm{h}\right)$ reduces the average heat-mass transfer efficiency by $1.45 \%$.

\section{Conclusion}

The efficiency of developed inclined-corrugated contact devices, made of polymer materials, was experimentally confirmed in practice. In the course of experiments, the following conclusions were made: the hydraulic resistance of proposed device is relatively low; the efficiency of heat-mass transfer processes at an irrigation density equal to 12-31 $\mathrm{m}^{3} /\left(\mathrm{m}^{2} \cdot \mathrm{h}\right)$ is at the level of existing analogues, while there is a wide range of operating gas 
rates from 1.7 to $3 \mathrm{~m} / \mathrm{s}$ without significant entrainment of liquid drops. The disinfection of liquid in the developed design of cooling tower is carried out by ozonation.
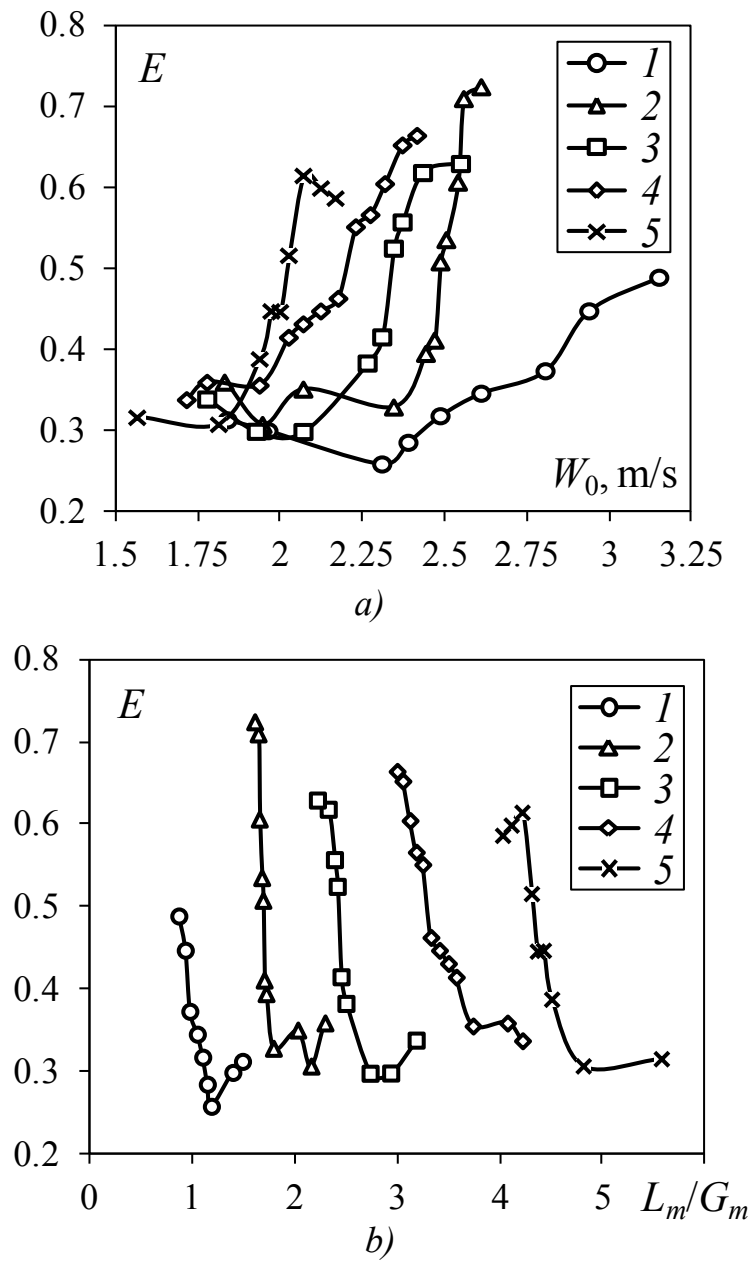

Fig. 3. The dependency of change in the heat-mass transfer coefficient on the fictitious air rate $(a)$ and the ratio of mass flow rates of liquid and gas phases $(b)$ at different irrigation densities $q, \mathrm{~m}^{3} /\left(\mathrm{m}^{2} \cdot \mathrm{h}\right)$ : $1-12 ; 2-18 ; 3-24 ; 4-31 ; 5-37$.

The research was conducted with funding from the RF President's grant project No. MK-417.2019.8.

\section{References}

1. E.V. Boev, S.P. Ivanov, V.G. Afanasenko, E.A. Nikolaev, Chem. and Pet. Eng. 45, 454 (2009)

2. V.S. Ponomarenko etc., Cooling towers of industrial and energy enterprises: a reference manual (Energoatomizdat, Moscow, 1998).

3. N.A. Merentsov, A.V. Persidskiy, V.N. Lebedev, N.A. Prokhorenko, A.B. Golovanchikov, Advances in Intelligent Systems and Computing 983, 547 (2019)

4. A.R. Iskandarova, N.D. Chichirova, Heat Supply News 165, 05 (2014) 
5. A.E. Ivanov, M.G. Berengarten, M.I. Klyushenkova, Chem. and Pet. Eng. 45, 526 (2009)

6. N.A. Merentsov, V.N. Lebedev, A.V. Persidskiy, V.A. Balashov, IOP Conf. Ser.: Earth and Environmental Science 288, 012106 (2019)

7. A.B. Golovanchikov, N.A. Merentsov, M.V. Topilin, A.V. Persidskiy, IOP Conf. Ser.: Earth and Environmental Science 288, 012089 (2019)

8. A.B. Golovanchikov, N.A. Merentsov, V.A. Balashov, Chem. and Pet. Eng. 48, 595 (2013)

9. M.I. Shilyaev, E.M. Khromova, A.R. Bogomolov, MATEC Web of Conf. 115, 08006 (2017)

10. G.V. Kuznetsov, D.V. Feoktistov, E.G. Orlova, S. Y. Misyura, V.S. Morozov, A.G. Islamova, Int. J. Heat Mass Transfer 126, 161 (2018)

11. N. Merentsov, A. Persidskiy, V. Lebedev, M. Topilin, A. Golovanchikov, Advances in Intelligent Systems and Computing 983, 560 (2019)

12. A.V. Persidskiy, N.A. Merentsov, V.N. Lebedev, A.B. Golovanchikov, IOP Conf. Ser.: Earth and Environmental Science 288, 012110 (2019)

13. A.V. Dmitriev, O.S. Dmitrieva, I.N. Madyshev, A.N. Nikolaev, Chem. and Pet. Eng. 53, 501 (2017)

14. A.V. Dmitriev, O.S. Dmitrieva, I.N. Madyshev, Chem. and Pet. Eng. 53, 430 (2017)

15. I.N. Madyshev, O.S. Dmitrieva, A.V. Dmitriev, A.N. Nikolaev, Chem. and Pet. Eng. 52, 299 (2016)

16. N.A. Merentsov, V.A. Balashov, D.Y. Bunin, V.N. Lebedev, A.V. Persidskiy, M.V. Topilin, MATEC Web of Conf. 243, 5 (2018)

17. N.A. Merentsov, A.V. Persidskiy, M.V. Topilin, V.N. Lebedev, V.A. Balashov, A.B. Golovanchikov, Journal of Phys.: Conf. Ser. 1278, 012024 (2019)

18. N.A. Merentsov, V.N. Lebedev, A.B. Golovanchikov, V.A. Balashov, E.E. Nefed'eva, IOP Conf. Ser.: Earth and Environmental Science 115, 012017 (2018)

19. A.B. Golovanchikov, V.A. Balashov, N.A. Merentsov, Chem. and Pet. Eng. 53, 10 (2017)

20. O.S. Dmitrieva, I.N. Madyshev, A.V. Dmitriev, J. Eng. Phys. Thermophy. 90, 651 (2017)

21. V.G. Afanasenko, F.Sh. Khafizov, N.F. Khafizov, S.P. Ivanov, E.V. Boev, Chem. and Pet. Eng. 43, 653 (2007)

22. I.N. Madyshev, A.I. Khafizova, O.S. Dmitrieva, E3S Web of Conf. 126, 00031 (2019)

23. A.V. Moshkarin, V.A. Kalatuzov, Bulletin of Ivanovo State Energy University 2, 1 (2006)

24. K.V. Chizh, A.S. Pushnov, M.G. Berengarten, Chem. and Pet. Eng. 50, 244 (2014)

25. A.S. Sokolov, A.S. Pushnov, M.V. Shapovalov, Chem. and Pet. Eng. 53, 1 (2017)

26. A.B. Golovanchikov, N.A. Merentsov, Advances in Intelligent Systems and Computing 983, 635 (2019)

27. Sokol B.A., Chermyshov A.K., Baranov D.A., Mass-transfer column packed-type devices (Infokhim, Moscow, 2009).

28. Kagan A.M., Laptev A.G., Pushnov A.S., Farakhov M.I., Contact packings in industrial heat-and-mass transfer apparatuses (Otechestvo, Kazan, 2013).

29. A.G. Laptev, V.A. Danilov, I.V. Vishnyakova, Thermal Eng. 51, 661 (2004) 